\title{
Evolutionary economics and policy: Introduction to the special issue
}

\author{
Thomas Brenner $^{1}$ (D) $\cdot$ Tom $^{\text {Broekel }}{ }^{2}$ \\ Published online: 30 October 2019 \\ (C) Springer-Verlag GmbH Germany, part of Springer Nature 2019
}

JEL classification $\mathrm{A} 11 \cdot \mathrm{H} 10 \cdot \mathrm{O} 30$

\section{Introduction: Evolutionary economics and policy}

The perspective of evolutionary economics on policy, its underlying theoretical implications and conception, as well as implications are different than that of neo-classical economics. In evolutionary economics, economic development "is seen as a continuing process in space and time" (Boulding 1991, p. 9). It implies that the economy and our knowledge about it are assumed to be continuously evolving. Consequently, universally valid laws and time-invariant facts do not exist therein, which includes policy. "During the process of policy making, and in its aftermath, the positive and normative knowledge that informs the actions of the agents involved can change through experience and induced inventive learning" (Witt 2003, p. 77).

On the one hand, this view makes policy, its design and consequences, much more complex and less straight-forward. On the other hand, it offers a more realistic understanding of the economy that amongst others, allows for adequately analyzing path-dependent and path-breaking dynamics as well as spatial processes shaping the economy. Of particular importance in this context are knowledge diffusion and innovation, which define the pace and direction of these developments. In addition, they shape (future) economic growth potentials. Therefore, it is not surprising that innovation policy is at the center of the policy-oriented evolutionary economics literature (e.g., Metcalfe 1994, Cantner \& Pyka 2001, Smith 2018) and of related fields such as regional policy (e.g., Lambooy \& Boschma 2001), environment policy (e.g., Faber \& Frenken 2009) and the literature on the relevance of institutions (e.g. Potts 2007).

Thomas Brenner

thomas.brenner@uni-marburg.de

1 Department of Geography, Philipps University Marburg, Deutschhausstr. 10, 35032 Marburg, Germany

2 UiS Business School, University of Stavanger, Stavanger 4036, Norway 
Notably, Witt (2003) puts forward that taking an evolutionary perspective on policymaking does not imply the need for a totally new concept of economic policy. Rather, the evolutionary approach adds a new perspective that emphasizes behavioral and contextual elements in the design and application of policy.

This special issue originated from the conferences of the German Section on Evolutionary Economics in Hannover (2016) and Marburg (2017) that were organized by the editors. It combines a series of theoretical and empirical articles that all share the evolutionary perspective on policy. In the theoretical works behavioral and institutional aspects are discussed that tend to be ignored by policy discussions in the existing non-evolutionary literature. For instance, this includes the coordination and directionality character of policies (Foray), the existence of behavioral biases in policy making (Schubert \& Schnellenbach), and the crucial role of institutions for economic development in general (Herrmann-Pillath) and for entrepreneurship in particular (Wegener). Similarly, the empirical works extent traditional empirical evaluations by shedding light on aspects that have received little attention so far. These include the stabilizing function of the largely publicly funded $\mathrm{R} \& \mathrm{D}$ sector in times of crisis (Günther et al.), the supportive role of this sector for regional economic restructuring (Brenner \& Pudelko), and the knowledge diffusion enhancing effects of R\&D subsidies (Broekel \& Bednarz).

Accordingly, this special issue gives testimony to the richness and breath of the Evolutionary perspective on policy analysis in general and innovation policy in particular. Moreover, it shows the complementary character of this perspective to the existing traditional economic literature.

\section{The articles in this special issue}

The contribution of Dominique Foray (this issue) broaches the issue of innovation policy in a fundamental way: It brings forward the argument that innovation policy should shift to a higher level of intervention. The author claims that the grand societal challenges need to be addressed with the help of non-neutral policies, which support more radical transformations and modernizations. He argues that there are three rationales for policy intervention: market failure, coordination problems, and directionality. Traditionally, innovation policy has been focusing on the first. While mainstream economists are skeptical of non-neutral policies addressing coordination and directionality, policy makers are actually already applying according measures. Put differently, researchers have to accept that coordination and directionality are part of policy and consequently, it needs to be on their agenda. Foray points towards this research gap and the question of how such policy measures should be designed. In particular, he identifies a number of policy design principles, such as human capital supply, the coupling of innovation and diffusion, as well as instruments chosen on the basis of domain-specific understanding. In sum, the paper provides a framework for developing non-neutral policy measures and highlights the need for further research on this issue.

The way policy-makers design innovation policy is addressed by Christian Schubert and Jan Schnellenbach (this issue). These authors propose to approach innovation policy with the framework of Behavioral Political Economy. This framework highlights 
the relevance of behavioral biases and heuristics, which the authors argue are responsible for a number of known policy problems . More precisely, they discuss that policymakers frequently have to rely on intuition and subjective understanding when facing situations of high complexity and uncertainty. Such is frequently the case in innovation processes, which are by nature characterized by potentially large but unknown outcomes, rapidly changing circumstances, few options for monitoring, as well as discrepancies between private and social interests. The authors discuss the working of a number of behavioral biases and heuristics on the basis of illustrative and known examples of innovation policy failures including the Matthew effect in the allocation of public R\&D funds, the sunk costs fallacy, and loss aversions in case of public R\&D investments. While the authors stress that the Behavioral Political Economy framework does not allow for predicting which biases or heuristics will become relevant under what circumstances, they argue and show the insightfulness of this perspective in ex-post evaluations of innovation policies that may then inform researchers and policymakers alike in the future.

Few sectors rely on more public funding than the R\&D sector. Given the relative stability of public financial inflows into this sector, the R\&D sector may contribute to the stabilization of countries' total economy in times of crisis. This becomes even more likely when governments deliberately use R\&D funding to counteract economic downturns. However, if and if so to what extent this is the case, has received little attention in literature so far. This motivates Jutta Günther, Maria Kristalova, and Udo Ludwig (this issue) to empirically explore the effect of an external shock, in this case an economy-wide recession, to the R\&D sector and its contribution to the total economy. The empirical investigation builds on an input-output analysis methodology and data for Germany, France, Austria, The Netherlands, and Finland. The findings confirm a crisis-resilient contribution of the R\&D sector to the total economy. Put differently, besides the well-documented positive contribution of R\&D to economies long-term development, the sector also induces stabilizing effects in times of economic crisis through its close links to policy.

The effects of two policy measures, public research and subsidies, on structural change in regions are examined by Thomas Brenner and Franziska Pudelko (this issue). They use data on the level of municipalities to analyze the causal effects of these policy activities on the change in the regional economic structures. So far, the literature exclusively offers insights into policy's effects on the economic development with respect to GDP and employment growth. The contribution of Brenner and Pudelko broadens the perspective by looking at effects in terms of stimulating municipalities to develop more dynamic and innovative economic structures. Their empirical results reveal that the examined policy activities seem to be primarily effective in less innovative and economically weak regions. In contrast, no effects are identified in case of economically prosperous regions.

Effects of subsidies are also in the focus of Tom Broekel and Marcel Bednarz (this issue). Such subsidies are intended to address market failures with respect to too low or lacking investments into R\&D activities in general. Recent modifications of this policy tool extent its aim by additionally incentivizing collaborative R\&D. As collaboration is an important channel for knowledge exchange and interactive learning, collaboration supported or initiated by $R \& D$ subsidies can be expected to facilitate interorganizational and inter-regional knowledge diffusion. However, empirical evidence 
for this effect has still been missing. The authors address this research gap using a novel dataset on joint R\&D projects subsidized by the German federal government and patent data. Yet, their empirical results fail to confirm a positive contribution of this policy tool to inter-regional knowledge diffusion. While this questions some of the positive effects frequently attributed to $R \& D$ subsidies, it also calls for new (empirical) approaches to policy evaluation.

The contribution by Carsten Herrmann-Pillath (this issue) advances the theory of economic institutions by merging North's theory of institutional change - especially the variant explained by North, Wallis and Weingast (2009) - with earlier ideas of North and Foucault. More precisely, he argues that informal institutions and beliefs play a systematic role as causal factors and should be more prominently considered. The paper offers such an extension to the theory of economic institutions and applies the advanced theory to the case of Russia. It investigates the different periods of the Russian history from the time of Catherine the Great until the rise of imperial capitalism under Putin. Thereby, it particularly looks at the interplay of informal institutions and the national state. Property rights and their evolution are in the center with other aspects of Russia's economic development being discussed as well.

Gerhard Wegner's work (this issue) similarly approaches the importance of policy and the institutional framework. His focus lies on entrepreneurial activities that he studies in the context of the transition of autocratic regimes with planned economies into market economies. The investigation thereby seeks to overcome the bias in most existing studies in evolutionary economics that tend to focus on Western-type political and institutional set-ups. Using a (neo-)Weberian conception of neo-patrimonialism as analytical tool, the author describes the institutional environment of post-communist countries and discusses a number of strategies of how entrepreneurial activities cope with neo-patrimonial systems. This theoretical contribution emphasizes the importance of taking political power into account when analyzing the development of political institutions from an evolutionary perspective.

\section{Concluding remarks}

This special issue highlights the richness of what the Evolutionary Economics perspective on innovation policy has to offer and, clearly, the topics discussed in the individual contributions (and elsewhere) are far from being exhaustedly researched. Nevertheless, we believe that a number of topics related to innovation policy demand particular attention from Evolutionary Economists in future research. We outline the (in our eyes) highly promising ones in the following.

"Big data" has become a buzz word, which's popularity is nevertheless an expression of a real underlying development. Data availability has been and still is tremendously increasing in terms of quantity of information (more and larger data sets) and in terms of quality (detailedness, level of observation, information richness, etc.). For instance, the establishment of accessible digital achieves of policy and journalistic documents opens the black box of policy making itself. Amongst others, this allows for studying the co-evolution of policy and socioeconomic structures at different (multiple) levels, across time, and beyond election results. In addition to a more encompassing view on policy (making), the "big 
data" revolution provides new information on innovation that will broaden our knowledge of innovation activities, which is still strongly shaped by insights on firm-internal manufacturing-based (product) R\&D activities. Unraveling the complex structures of innovation processes' embeddedness into dynamic multi-agent networks is crucial for understanding innovation in the age of the knowledge and service economy. Moreover, it also loudly calls for an evolutionary research approach! However, to open and exploit the treasure chests of "big data", Evolutionary Economics needs to possess the necessary keys, which, in this case implies being at the forefront of exploring and utilizing novel empirical methodologies. Important strands of methodological developments in this context are automatic content/text analysis methods and statistical tools dealing with fine-grid geographic or geo-coded data (e.g., used by Brenner and Pudelko in this issue).

As pointed out by Foray in his contribution to this issue, policy makers face grand societal challenges for which traditional approaches do not provide adequate solutions. We believe that Evolutionary Economics can help in providing a better understanding of these problems and potential solutions. Current challenges that will continue to be issues for the society and policy makers in the future are, for example, climate change, migration, (regional) inequalities, and populism. These problems involve complex dynamics with self-augmenting processes and path-dependencies, which have always been at the heart of Evolutionary Economics and for which it has shown to be highly capable to deal with. While Evolutionary Economists have already contributed to the understanding of these problems and the involved dynamics, policy evaluation is still dominated by types of diff-and-diff analyses, which are short-term comparative approaches evaluating the situations before and after a policy intervention for treated and non-treated units. Non-linear and path-dependent dynamics that are triggered and reenforced by policy measures and which unfold over longer time periods are not adequately considered by such analyses. This is where Evolutionary Economics has a lot to offer. However, to do so Evolutionary Economists have to take a more active role in policy evaluation and need to develop more standardized and better tools dealing with this complexity.

Funding The authors received no financial support for the research, authorship and publication of this article.

\section{Compliance with Ethical Standards}

Conflict of interest Thomas Brenner and Tom Broekel declare that they have no conflict of interest.

\section{References}

Boulding KE (1991) What is evolutionary economics? J Evol Econ 1:9-17

Cantner U, Pyka A (2001) Classifying technology policy from an evolutionary perspective. Res Policy 30: $759-775$

Faber A, Frenken K (2009) Models in evolutionary economics and environmental policy: Towards an evolutionary environmental economics. Technol Forecast Soc Chang 76:462-470 
Lambooy JG, Boschma RA (2001) Evolutionary economics and regional policy. Ann Reg Sci 35:113-131 Metcalfe S (1994) Evolutionary economics and technology policy. Econ J 104:931-944

North DC, Wallis J, Weingast BR (2009) Violence and Social Orders. A Conceptual Framework for Interpreting Recorded Human History. Cambridge University Press, Cambridge

Potts J (2007) Evolutionary institutional economics. J Econ Issues 41:341-350

Smith K (2018) Innovation Policy in an Evolutionary Context. In: Saviotti P, Metcalfe S (eds) Evolutionary Theories of Economic and Technological Change. Routledge, London

Witt U (2003) Economic policy makingin evolutionary perspective. J Evol Econ 13:77-94

Publisher's note Springer Nature remains neutral with regard to jurisdictional claims in published maps and institutional affiliations. 